\title{
ADEOUAÇÃO DA LEI DE FALÊNCIAS E RECUPERAÇÃO DE EMPRESAS BRASILEIRA (LFRE) - 11.101/05 AO MERCADO, APÓS CINCO ANOS DE VIGÊNCIA
}

\author{
Paulo Roberto Colombo Arnoldi*
}

\begin{abstract}
SUMÁRIO: 1. Introdução 2. A Crise Econômico-FinanceiraIntemacional de Setembro de 20083. Inovações Introduzidas pela Lei de Falências e Recuperação de Empresas 11.101/054. As Imperfeições, Lacunas e Conflitos da Lei 5. Conclusão 6. Bibliografia
\end{abstract}

- Resumo: A LFRE - Lei de Falências e Recuperação de Empresas brasileira 11.101/05 completou cinco anos de vigência, após revogar o antigo Decreto Lei 7.661/45. O teste de aprovação do novo diploma legal foi antecipado em alguns anos, após a eclosão da crise econômico-financeira internacional, em setembro de 2008, com a quebra do Banco Lehman Brothers, nos Estados Unidos. A despeito dos avanços introduzidos pela nova sistemática legislativa, que trouxe sensíveis melhoras ao ambiente de negócios, alguns dispositivos legais ainda dão ensejo a polêmicas na esfera do Judiciário, por imperfeição, inexatidão ou lacuna, em vista de não se ter chegado a um consenso. Nesse sentido, entendemos que esse conjunto normativo está ainda a merecer algumas melhorias. O tempo se incumbirá de detectá-las, ajustando a norma legal à realidade do mercado, tendo o Poder Judiciário papel fundamental na efetivação desses ajustes.

- Palavras-chave: Direito; falência; recuperação de empresas; mercado.

- Abstract: The brazilian Bankruptcy Law and Business Recovery 11.101/05 completed five years of operation, having superseded the old Decree 7.661/45. The acceptance test of the new statute was anticipated in some years after the outbreak of international economic and financial crisis in September 2008 with the collapse of Lehman Brothers, in the United States. Despite the advances introduced by the new system of legislation, which brought improvements to sensitive business environment, some legal provisions still give rise to controversies in the realm of the judiciary, by imperfection, inaccuracy or omission, in order not to have reached a consensus. In this sense, we understand that this set of rules is still deserve some improvements. Time will be responsible for detecting them, setting the legal standard to the market reality, and the Judiciary key role in effecting these adjustments.

- $\quad$ Keywords: Law; bankruptcy; business recovery; market.

\section{1 - INTRODUÇÃO}

A LFRE - Lei de Falências e Recuperação de Empresas brasileira 11.101/05 completou cinco anos de vigência no dia 9 de fevereiro, após revogar o antigo Decreto Lei 7.661/45 do século passado, que perdurou por 60 anos, produzindo bons frutos durante esse período, mas com o dinamismo e a complexidade da economia tornouse obsoleto ante as novas exigências do mercado.

A pergunta que se faz após este período de cinco anos é se a lei está aprovada ante a realidade e as exigências do mercado, ou ainda merece reparos na sua

* Professor Doutor do Curso de Direito da UNESP, Campus Franca; Presidente do Capítulo Brasileiro do IIDC - Instituto Iberoamericano de Derecho Concursal. 
confecção, ou no nível de eficiência.

A resposta não é simples, aparecendo críticos que a condenam e outros ressaltam seus méritos. Passemos, portanto, à sua análise, para se ter uma ideia do quadro em que ocorreram os acontecimentos.

\section{2-A CRISE ECONÔMICO-FINANCEIRA DE SETEMIRO DE 2008}

Entendemos que o teste de aprovação do novo diploma legal foi antecipado em alguns anos, com a eclosão da crise econômico-financeira internacional, em 15 de setembro de 2008, com a quebra do Banco Lehman Brothers, ocorrida nos Estados Unidos. Essa crise gerou efeitos catastróficos, só comparáveis com a ocorrida em 1929, também nos EUA, com a quebra das Bolsas de Valores. Os efeitos da crise espalharam-se rapidamente pelo resto do mundo, de forma a impactar negativamente a economia de muitos países, que viram seus PIBs despencarem rapidamente - caso do Brasil, que caiu a -0,2 (quando a previsão era positiva para cerca de 5\%). Embora negativo, o Brasil acabou se saindo bem melhor que economias desenvolvidas como EUA (queda a -2,4\%), Alemanha (-5\%), Reino Unido (-4,9\%), Japão (-5,1\%) e Rússia ($7,9 \%$ ). O México, que tem sua economia atrelada à americana, também tombou a 6,5\%. Portanto, como se observa pelos índices, a crise assustou o mundo.

Cumpre salientar que, decorridos 3 anos, esta crise ainda não está devidamente solucionada, em vista que vários países ainda terão crescimento negativo neste ano de 2010, com altos índices de desemprego, como é o caso de alguns países da Comunidade do Euro, que tiveram crescimento anualizado de 0,5\%. A Espanha ainda será negativo, dado a sua crítica situação econômica e alto desemprego, beirando a casa dos 19\%. A Grécia, Portugal, Irlanda e Itália - entre outros também da região do Euro, encontram-se em situação fiscal delicada, gerando um certo temor de não pagamento de suas dívidas. A Rússia e alguns países do Leste Europeu, para ficarmos em alguns exemplos, também se encontram em situação delicada (fonte: Jornal Valor, SP - 12 a 14 de março de 2010, sexta-feira e fim de semana p. A-3).

A despeito da anarquia que se instalou de lá para cá, pouco mudou. Os mercados e os banqueiros ainda controlam a situação, apesar de os Estados Unidos terem aprovado um regime regulatório mais rígido sobre os bancos e os salários dos executivos terem sido controlados das gratificações exorbitantes, com cobrança de algum desempenho. O Comitê de Reguladores da Basileia está impondo exigências de capital mais rígidas para 2018. O que mudou apenas é o fato de as pessoas estarem mais pobres (de: Phillip Stephens para o Financial Times, in: Jornal Valor, segundafeira, 2 de agosto de 2010, p. A-11, "Três anos após a crise, os mercados reinam novamente").

No caso específico do Brasil, os efeitos da crise foram graves, mas bem menos impactantes que em outros países, devido a uma política macroeconômica sustentada, com:

- metas de inflação consistentes;

- $\quad$ sistema bancário sólido; e 
- grandes reservas econômicas em moeda forte (cerca de US\$240 bi).

Também contribuiu positivamente o grande mercado consumidor interno, no qual cerca de 26 milhões de trabalhadores tiveram sensivelmente melhorados seus salários nos últimos cinco anos, em virtude do aumento real do salário mínimo implementado pelo governo Lula nestes últimos oito anos, e migraram para a "classe $C$ " - com renda mensal variando entre $R \$ 1.100,00$ e $R \$ 4.800,00$, ou entre 600 e 2.700 dólares (fonte: Jornal Valor, 23 de fevereiro de 2010, p. D-10, terça-feira, Caderno Eu \& Livros).

Segundo previsões do J.P. Morgan o Brasil deverá registrar uma das maiores taxas de crescimento do mundo em 2010 , previsão de 7,2\% - ritmo de expansão que só deve ser superado por alguns países asiáticos, com destaque para a China (10\%), Índia (8\%) e Taiwan (7\%), além dos Estados Unidos, com 3,4\% (fonte: Jornal Valor, sexta-feira e fim de semana, 12 a 14 de março de 2010, p. A-3).

Embora o quadro econômico tenha sido ameno, "uma marolinha, e não um tsunami" - como se referiu o presidente Lula - muitas empresas não estavam preparadas, sendo pegas de surpresa, não restando alternativa senão recorrer aos novos institutos previstos na atual legislação concursal brasileira.

Apesar de indesejável, esse quadro econômico-financeiro entre as empresas serviu para um "teste de fogo" para a lei neste curto prazo de vigência, no sentido concreto de se ter elementos para analisá-la e propor melhorias em seu texto.

A nova sistemática incorporou-se ao ordenamento jurídico como uma das exigências do Banco Mundial para o Brasil integrar-se no contexto global com maior segurança jurídica e melhoria no ambiente de negócios, além de maior facilidade de acesso ao crédito e solução de mercado para empresas em crise. Introduziu como grande novidade na sua concepção os Institutos da Recuperação Extra-Judicial, Judicial e Especial para as Micro Empresas (MEs) e Empresas de Pequeno Porte (EPPs).

Esses institutos constituíram-se em um grande suporte para as empresas em dificuldade econômico-financeira momentânea, mas com potencial de produtividade, de modo a evitar desta forma o encerramento prematuro das atividades, com grandes conseqüências sociais e econômicas para a comunidade e para o mercado, com possibilidade de agravamento do quadro de crise de outras empresas que com as primeiras se relacionam.

Nesse sentido, um volume expressivo de empresas teve necessidade de se socorrer desses procedimentos para estancar o quadro de crise que vinha ocorrendo, de forma a obter bons resultados quanto a manutenção de suas atividades produtivas, da força de trabalho, do acesso ao crédito e da arrecadação de tributos, gerando dessa forma benefícios para toda a coletividade e ao Estado. Sem a nova lei muitas empresas já não teriam sobrevivido e sucumbiriam ante a falta de instrumentos jurídicos que lhes desse amparo. 


\section{3-INOVAÇÕES INTRODUZIDAS PELA LEI DE FALÊNCIAS E RECUPERAÇÃO DE EMPRESAS-11.101/05}

Entre as principais inovações que foram introduzidas nesse novo ordenamento destacamos:

a) Substituição dos arcaicos institutos da Concordata Preventiva e Suspensiva, que nada mais era do que uma postergação do agravamento do quadro de crise econômico-financeira, e com a quebra da empresa acarretando prejuízo aos credores - que nada mais tinham a receber - pelos institutos da Recuperação Extra-Judicial, Judicial e Especial para Micro Empresas e Empresas de Pequeno Porte. Com essa alteração, tornou-se mais ágil e prático esse difícil período enfrentado pelas empresas devedoras. Exemplo: empresas com títulos protestados não podiam se beneficiar da antiga Concordata; atualmente, sob a égide da nova lei, essa circunstância não é fato impeditivo para concessão do benefício da Recuperação Judicial;

b) Outro aspecto que merece destaque é que, para se iniciar um procedimento de Recuperação Judicial, não se exige do devedor a necessidade de estar solvente, ou seja, possuir ativo superior ao passivo, cabendo apenas à empresa demonstrar a efetiva viabilidade da atividade econômica;

c) Possibilidade de venda antecipada dos bens, alcançando melhor preço dos ativos em favor dos credores, ao contrário de sua venda ao final, quando os mesmos estavam totalmente deteriorados;

d) Quanto ao Instituto da Falência, este recebeu uma nova e moderna roupagem, de forma a possibilitar um desenvolvimento mais rápido de seus atos, em detrimento de outros procedimentos, objetivando dar maior eficiência e celeridade quanto à venda dos bens para outras empresas, com a perspectiva de não se por fim a atividade econômica, mas uma possibilidade de sua preservação em benefício dos credores;

e) Preocupação com a função social da empresa e, consequentemente, salvaguardar os interesses dos obreiros, mantendo seus postos de trabalho e as atividades da própria unidade produtiva;

f) Maiores poderes concedidos à Assembléia Geral de Credores e ao Comitê de Credores por ela designada, como forma de agilizar os entendimentos entre credores e devedor, que são os maiores interessados na solução do conflito;

g) Substituição da figura do Síndico pela do Administrador Judicial, profissional teoricamente mais preparado e com formação universitária escolhido entre advogados, contabilistas, administradores de empresas e economistas; 
h) Maior rigor na apuração e punição dos crimes falimentares, bem como a criação de novas figuras delituosas; e

i) Criação do Plano de Recuperação Judicial - Com as mudanças introduzidas as empresas passaram a ter um horizonte mais flexível para pagamento de seus débitos, antes limitado a dois anos. Isso foi possível por meio do Plano, grande inovação da lei, a ser elaborado pela empresa em dificuldade e apresentado em Assembléia de Credores. Uma vez aprovado, com prazos determinados no documento - muitos entre 10 e 15 anos - o Plano estabelece as estratégias de saneamento. Após dois anos de cumprimento do Plano, se a empresa se mantiver em dia com sua obrigações, a lei estabelece o direito de requerer o encerramento do processo. Se o pedido for aceito, o Plano passa a funcionar como qualquer contrato e, portanto, sujeito a todos os seus riscos. Se o contrato deixar de ser cumprido, a companhia estará sujeita a execução judicial ou quebra. A não apresentação do Plano no prazo de 60 dias implica na quebra automática.

\section{4-AS IMPERFEIÇÕES, LACUNAS E CONFLITOS DA LEI}

A despeito dos avanços introduzidos pela nova sistemática legislativa, que trouxe sensíveis melhoras no ambiente de negócios, alguns dispositivos legais promovem, todavia, ensejo a polêmicas na esfera do Judiciário, por imperfeição, inexatidão ou lacuna não permitirem a chegada a um consenso. Vejamos alguns casos:

a) O artigo 49, parágrafo 3.o, exclui os créditos garantidos por alienação fiduciária do âmbito da Recuperação Judicial. Normalmente esses credores são instituições financeiras, as quais defendem a sua exclusão, alegando que é uma proteção oferecida aos bancos, em detrimento da própria recuperação da empresa. Em contrapartida, outros, por sua vez, observam que tal medida promoveu o avanço na consolidação do sistema de garantias no Brasil, já que beneficia tanto os bancos - sujeitos a exposição de um menor risco - quanto as empresas em dificuldade, que podem contar assim com maior facilidade na obtenção do crédito;

b) Outra questão que merece um melhor equacionamento quanto à sua aplicação, trata-se do referente ao Juízo Universal da Recuperação Judicial, que suscita conflito de competências entre as Varas Especializadas em Recuperação Judicial e Falências - denominadas em alguns estados brasileiros de Varas Empresariais - e a Justiça do Trabalho. Esta última, em muitos casos, procurando salvaguardar os direitos dos obreiros, tem determinado o prosseguimento das execuções trabalhistas, sem aguardar a homologação do Plano de Recuperação Judicial, prejudicando dessa forma o andamento e até a viabilidade da recuperação da empresa; 
c) A Recuperação Extra Judicial - que na prática mostra-se como uma tentativa amigável de solução dos problemas econômico-financeiros da empresa devedora com seus credores, sem a intervenção do aparato judiciário, a não ser por ocasião de sua homologação. O que se tem observado é que esse procedimento acaba sendo resolvido entre as próprias partes, por meio da transação no âmbito contratual privado, dispensando a participação do Poder Judiciário. Busca-se essa alternativa como forma de baratear os custos do procedimento e obter maior flexibilidade nos acordos, além da sua agilização;

d) Nas Recuperações Judiciais, os custos despendidos para sua execução se demonstram muito elevados, em vista do envolvimento de muitos profissionais especializados para elaboração do Plano de Recuperação Judicial e publicação de custosos editais, o que tem afastado algumas empresas de se socorrerem desse instituto, de forma que busquem outras alternativas mais baratas, quando possível, como a Recuperação Extra Judicial ou a Negociação Direta, tipo concordata branca.

Fazendo um balanço da LFRE - Lei de Falências e Recuperação de Empresas (in: Jornal Valor, quarta-feira, 16 de junho de 2010, p. E-2), Jorge Queiróz ainda lembra dos que entendem que a legislação não tem produzido os efeitos esperados, argumentando que somente leis não salvam empresas; engenharias jurídicas também não; posto que operadas por profissionais que conviveram durante toda a carreira com o antigo decreto de 1945, levará tempo até que o "espírito do sistema" seja devidamente assimilado.

Alega que os Planos, em sua maioria, restringem-se à ampliação dos prazos e deságios, além de mal concebidos por serem elaborados por profissionais que não são da área. Cita o caso da VARIG - primeira recuperação da nova LFRE - como um desastre. A Companhia recuperanda ainda não retomou a normalidade de suas operações, tampouco a credibilidade. Os ativos mais importantes, inclusive a marca, foram transferidos para a nova empresa ("VARIG nova"), operação conhecida como "limpeza de ativos" - deixando alguns ativos para a "velha Varig". A "VARIG nova" (VarigLog) foi vendida por US\$ 24 milhões e em seguida para a Gol por US\$ 320 milhões, sem sucessão trabalhista ou tributária, amparada por decisão do Superior Tribunal de Justiça (STJ).

Outro caso que cita é o da VASP, que ao entrar em recuperação apenas retardou a falência. Também o setor de frigoríficos e agronegócio teve peculiaridades controvertidas, consideradas pelo mercado como verdadeiras operações de 'subprimes' brasileiras. Bilhões de reais foram desperdiçados com a ineficácia dos agentes envolvidos.

Critica também o Judiciário por ainda não terem sido criadas Varas Regionais Especializadas que dariam maior eficiência e êxito ao sistema; conclama para urgente 
reforma do CPC - Código de Processo Civil, como forma de diminuir os recursos existentes, os quais têm criado grande carga de trabalho para os magistrados e tribunais.

Conclama ainda que tudo o que se refere às empresas deva ser tutelado exclusivamente pelo Juízo Universal, inclusive os impostos; alega que o Comitê de Credores, órgão vital para colaborar para a recuperação da empresa, tem sido pouco utilizado - cita os casos do Banco Santos, que por ter sido formado por profissionais independentes e especializados foi fator determinante para serem recuperados $R \$$ 843 milhões ou $25 \%$ do passivo, fato que considerou inédito e modelo.

Em contrapartida, como modelo de fracasso cita a questão da VARIG, na qual a criação intempestiva do Comitê originou grande desequilíbrio nas funções dos órgãos envolvidos, impondo pesado ônus ao Juízo e ao Administrador, sobrecarregando-os com atividades não inerentes ao seus ofícios.

Em suma, diz que o resultado deste ciclo inicial frustrou a expectativa, e caso não haja correção de rumo pode comprometer a confiança na LFRE.

A despeito dos argumentos ponderáveis de Jorge Queiróz em seu balanço sobre os cinco anos da nova Lei de Falências e Recuperação de Empresas, podemos afirmar que os benefícios e conquistas introduzidos pela Lei 11.101/05 foram relevantes e expressivos, devendo ser comemorados pelos mundos jurídico e econômico, e em especial pelas empresas, que em determinado momento podem passar por um estado de crise econômico-financeira e agora contam com instrumentos jurídicos de amparo. Todavia, é necessário que tenham potencial de se manter e se recuperarem no mercado, atingindo desta forma seu objetivo social, que é salvaguardar a manutenção dos postos de trabalho, arrecadar os tributos indispensáveis à manutenção do Estado e cumprir sua atividade-fim.

Os fatos falam por si. Segundo dados divulgados no fim de 2009 (9 de dezembro, Jornal Valor, p. E-1) e também no início de 2010 pela Serasa.Experian, maior empresa brasileira de assessoramento a bancos para divulgação de informes, ocorreu uma queda expressiva no número de falências decretadas no Brasil - de 2.786 ocorrências em 2005 (ano da entrada em vigência da nova lei) para $1.779 \mathrm{em}$ 2009 (auge da crise econômico-financeira mundial).

Em contrapartida, houve um significativo aumento de pedidos de Recuperação Judicial (693 em um ano), de forma a demonstrar, a nosso ver, que a lei está atendendo seu objetivo - em vez de liquidar o negócio, está salvando/ recuperando empresas com potencial econômico produtivo. Desde 2005 onze grandes empresas brasileiras conseguiram finalizar o processo, de um total de 122 pedidos deferidos. Nesses casos, os Planos foram rigorosamente cumpridos, conforme determina a lei, o que representa a volta à normalidade de suas atividades sem a chancela de recuperação.

\section{5-CONCLUSÃO}

Entendemos que, salvo melhor juízo e análise que se possa fazer deste novo diploma legal, a LFRE foi bem vinda, trazendo avanços para o setor econômico e o 
empresarial, que clamava por oportunidades para manter suas atividades em funcionamento. Caso tivesse a Lei sido implementada há mais tempo - como era desejo de muitos empresários e juristas - muitas grandes empresas brasileiras teriam sido salvas, por exemplo o tradicional Magazine Mappin, orgulho dos paulistanos, a G.Aronson, gigante do setor de eletrodomésticos, ou ainda a VASP e a Transbrasil, tradicionais empresas que desfalcaram o setor aéreo, reduzindo a competitividade do mercado e prejudicando os usuários e até mesmo outras empresas. Se essas empresas mencionadas tivessem sido mantidas, inegavelmente milhares de empregos seriam salvos, salvaguardando a renda das famílias, com benefícios para o Estado e para a comunidade.

Apesar de várias empresas importantes para o mercado brasileiro terem quebrado, outras também relevantes foram beneficiadas e recuperadas desde 2005, como é o caso - entre outras - da Recrusul Turismo e Agenciamentos, Cory, Eucatex, Refisa, Refrima, Prata Confecçóes, Cristal Calçados, VARIG, Nordeste Linhas Aéreas, Rio Sul Linhas Aéreas e Viação Aérea Riograndense. Além de possibilitar a sobrevivência delas a Recuperação significou também respeito ao mercado onde atuam e aos próprios credores (Jornal Valor, 9 de dezembro de 2009, p. E-1).

Apesar dos avanços, não devemos perder de vista, entretanto, que esse conjunto normativo ou micro-sistema está ainda a merecer, conforme ressaltado, algumas melhorias. O tempo se incumbirá de detectá-los, ajustando a norma legal à realidade do mercado. Nesse aspecto o Poder Judiciário desempenhará papel fundamental para fazer esses ajustes. Vamos esperar para ver e conferir.

\section{BIBLIOGRAFIA}

ARNOLDI, Paulo Roberto Colombo. A Nova Lei Concursal Brasileira. Lemos \& Cruz, Franca-SP, 2007.

LAMUCCI, Sérgio; e outros. Investimento cresce o triplo do consumo no quarto trimestre. Jornal Valor, SP, 12 a 14 de março de 2010, sexta-feira e fim de semana, p. A-3.

MARESKA, Tiveron Salage; BORGES, Leandro Vilarinho. Os cinco anos da nova Lei de Falências. Jornal Valor, SP, terça-feira, 9 de fevereiro de 2010, Caderno Legislação \& Tributos, p. E-4.

OLIVEIRA, João Carlos. Os 10 dias que mataram o Bear Stearns. Jornal Valor, SP, terça-feira, 16 de março de 2010, Caderno Eu \& Livros, p. D-16.

QUEIRÓZ, Jorge. Balanço da Lei de Recuperação de Empresas. Jornal Valor, SP, quartafeira, 16 de junho de 2010, Caderno Legislação \& Tributos, p. E-2.

SOUZA, Amauri; LAMOUNIER, Bolívar. A classe Média Brasiléia - Ambições, Valores e Projeto da Sociedade. Editora Campus, SP, 2010.

ZINIA, Baeta; AGUIAR, Adrian. Empresas se recuperam e crescem. Jornal Valor, SP, quarta-feira, 9 de dezembro de 2009, Caderno Legislação \& Tributos, p. E-1. 